\title{
Climate effect of an integrated wheat production and bioenergy system with Low Temperature Circulating Fluidized Bed gasifier
}

Sigurjonsson, Hafthor Æggir; Elmegaard, Brian; Clausen, Lasse Røngaard; Ahrenfeldt, Jesper

Published in:

Applied Energy

Link to article, DOI:

10.1016/j.apenergy.2015.08.114

Publication date:

2015

Document Version

Peer reviewed version

Link back to DTU Orbit

Citation (APA):

Sigurjonsson, H. ÆE., Elmegaard, B., Clausen, L. R., \& Ahrenfeldt, J. (2015). Climate effect of an integrated wheat production and bioenergy system with Low Temperature Circulating Fluidized Bed gasifier. Applied Energy, 160, 511-520. https://doi.org/10.1016/j.apenergy.2015.08.114

\section{General rights}

Copyright and moral rights for the publications made accessible in the public portal are retained by the authors and/or other copyright owners and it is a condition of accessing publications that users recognise and abide by the legal requirements associated with these rights.

- Users may download and print one copy of any publication from the public portal for the purpose of private study or research.

- You may not further distribute the material or use it for any profit-making activity or commercial gain

- You may freely distribute the URL identifying the publication in the public portal 


\title{
Climate Effect of an Integrated Wheat Production and Bioenergy System with Low Temperature Circulating Fluidized Bed Gasifier
}

\author{
Hafthor Ægir Sigurjonsson ${ }^{\mathrm{a}, *}$, Brian Elmegaard ${ }^{\mathrm{a}}$, Lasse Røngaard Clausen ${ }^{\mathrm{a}}$, Jesper \\ Ahrenfeldt ${ }^{\mathrm{b}}$ \\ ${ }^{a}$ Department of Mechanical Engineering, Technical University of Denmark, Nils Koppels Alle 403, 2800 Kongens Lyngby, Denmark \\ ${ }^{b}$ Department of Chemical Engineering, Technical University of Denmark, Frederiksborgvej 399, 4000 Roskilde, Denmark
}

\begin{abstract}
When removing biomass residues from the agriculture for bioenergy utilization, the nutrients and carbon stored within these "residual resources" are removed as-well. To mitigate these issues the energy industry must try to conserve and not destroy the nutrients. The paper analyses a novel integration between the agricultural system and the energy system through the Low Temperature Circulating Fluidized Bed (LT-CFB) gasifier from the perspective of wheat grain production and electricity generation using wheat straw, where the effects of removing the straw from the agricultural system are assessed along with the effects of recycling the nutrients and carbon back to the agricultural system. The methods used to assess the integration was Life Cycle Assessment (LCA) with IPCC's 2013100 year global warming potential (GWP) as impact assessment method. The boundary was set from cradle to gate with two different functional units, $\mathrm{kg}$ grain and $\mathrm{kWh}$ electricity produced in Zealand, Denmark. Two cases were used in the analysis: 1 . nutrient balances are regulated by mineral fertilization and 2. the nutrient balances are regulated by yield. The analysis compare three scenarios of gasifier operation based on carbon conversion to two references, no straw removal and straw combustion. The results show that the climate effect of removing the straws are mitigated by the carbon soil sequestration with biochar, and electricity and district heat substitution. Maximum biochar production outperforms maximum heat and power generation for most substituted electricity and district heating scenarios. Irrespective of the substituted technologies, the carbon conversion needs to be $80-86 \%$ to fully mitigate the effects of removing the straws from the agricultural system. This concludes that compromising on energy efficiency for biochar production can be beneficial in terms of climate change effect of an integrated wheat production and bioenergy system.
\end{abstract}

Keywords: Life Cycle Assessment, Wheat production, Straw utilization, Thermal Gasification, Carbon soil sequestration

\section{Introduction}

Climate change, security of supply and depletion of fossil fuels have become increasingly well-known issues, and the combination of the three has instigated a worldwide attention on finding pathways for sustainable energy supply

\footnotetext{
${ }^{*}$ Corresponding author

Email address: hafs ig@mek.dtu.dk (Hafthor Ægir Sigurjonsson )
} 
$[1,2]$. Increased use of biomass feedstock for transport, power and heat generation are generally perceived as relevant methods to mitigate these concerns. However parallel to these before-mentioned issues are problems associated with food supply, population growth, land use, essential mineral depletion and soil degradation. All of which contribute to the increasing awareness of biomass as both an energy and food resource.

Moving from a fossil fueled energy system towards greater reliance on renewables, requires cautiously designed allocation of the obtainable resources and a highly flexible system [3]. In this perspective, gasification of biomass has proven its potential. A Low Temperature Circulating Fluidized Bed gasifier (LT-CFB), currently termed Pyroneer, was developed to be able to operate on biomass feedstock with high ash content that has proven difficult to use in other systems, e.g. straw, manure fibers, sewage sludge, organic waste etc. [3].

Biomass residues from the agricultural industry are normally taken to be readily available to the energy sector, and obvious to exploit for producing power, heat and fuels. However, what is not so obviously seen from the energy system's perspective is the fact that together with the removal of biomass residues from the agricultural sector, the nutrients and carbon within them are also removed. This entails the need to add nutrients and possibly carbon to the agricultural fields in order to maintain soil fertility and soil carbon content. This has been highlighted with recent environmental impacts studies on bioenergy. Djomo et al. [4] report the change in soil organic carbon for perennial energy crops to be climate change mitigating, conversely Sastre et al. [5] show that loss of carbon of soil carbon is the greatest contributor to the climate change effect of a bioenergy system utilizing wheat straw. It is also one of the conclusions of Yang et al. [6] and Parajuli et al [7] that carbon loss from agricultural residue removal is an important contributor to climate change in a bioenergy system. Two latter papers discuss the impact of atmospheric carbon load due to biogenic carbon emissions, Parajuli et al. [7] uses the approach of Petersen et al. [8], which is very similar to the work of Guest et al. [9] and [10] for forestry systems.

Kuligowski et al. [11] concluded from a field study that ash derived from a low-temperature gasification of the fiber fraction from anaerobically digested pig slurry has the potential to be used to maintain phosphorus levels in agricultural soils. Müller-Stöwer et al. [12] further concluded that ash from low temperature gasification of biomass can replace mineral fertilizer. Moreover, in addition to the recycling of valuable nutrients, the use of ash containing recalcitrant carbon fractions could maintain or even increase soil organic carbon stocks and thus contribute to carbon sequestration as suggested by Brandao et al. [13]. Recently Veronika et al. [14] contributed to this discussion by experimental results indicate that gasification biochar is very stable in soil and has good potential for a longterm carbon sequestration in soil.

Realizing this, and integrating it into a bioenergy concept, can create the foundation of a flexible and sustainable use of biomass resources, and make such a bioenergy system a genuinely climate neutral or even climate mitigating source of energy. Nguyen et al. [15], [16] used life cycle assessment (LCA) to assess the environmental concerns of using wheat straw in the energy system and applying the ash back to the field using both combustion and gasification technologies. However, it was noted that more research was required on the issue to conclude on those results. This article is meant to shine a light on those issue and by further analyzing the carbon conversion (CC) in a polygeneration energy system producing; electricity, district heat and carbon rich "fertilizer" (named GBC in the article or gasification biochar). The system will be analyzed for three operational scenarios in the gasifier, i.e. maximum product gas production, maximum biochar production and a climate neutral scenario. These scenarios are compared with two reference scenarios, one where the straws are not harvested and thus no heat or power are generated, another with straw removal and combustion instead of gasification in the energy system.

Moreover, it is of interest to include in the analysis the total wheat production at a specific location in Denmark and to analyse more closely the consequences of the changes in soil nitrogen dynamics. This is done by computing a novel inter-connected model of the agricultural system and the energy system. Which combines carbon in soil simulation in C-TOOL [17], [18], energy system simulation with Dynamic Network Analysis (DNA) [19], Life Cycle inventory and Impact Assessment processing with Brightway2 [20], along with substance flow calculations and atmospheric carbon decay simulation. 


\section{Methods}

\subsection{System Description}

Energy system utilizing wheat straw for heat and power generation is analysed. Ashes and biochar (GBC) are recycled back to the agricultural system, GBC is considered the third product of the energy system. Three scenarios (S1-S3) and two reference cases (RA and RB) are modelled.

\section{Scenarios.}

- RA: Straw not harvested. Straws are not removed from the field and thus no electricity and heat production.

- RB: Straw direct combustion. Straws are removed from the field and combusted. Bottom ash is recycled back to the field and fly ash is landfilled.

- S1: Maximum heat and power generation. Straws are removed from the field and gasified with carbon conversion $^{1}$ (CC) of $95 \%$, gas produced is combusted in an conventional combined heat and power (CHP) steam cycle and the GBC is returned to the field.

- S2: Climate neutral. Like High CC, but with a carbon conversion adjusted to make the mitigating effect of carbon soil sequestration equal to the impact of removing and utilizing the straw in the energy system.

- S3: Maximum biochar production Like High CC, but the lowest possible carbon conversion is found from system simulation.

A simple schematic of the complete system including the agriculture and energy conversion is presented in Figure 1. Grain yield per hectare is an input to the model and was assumed to be 8.0 tonnes. The harvestable residues, i.e., straw

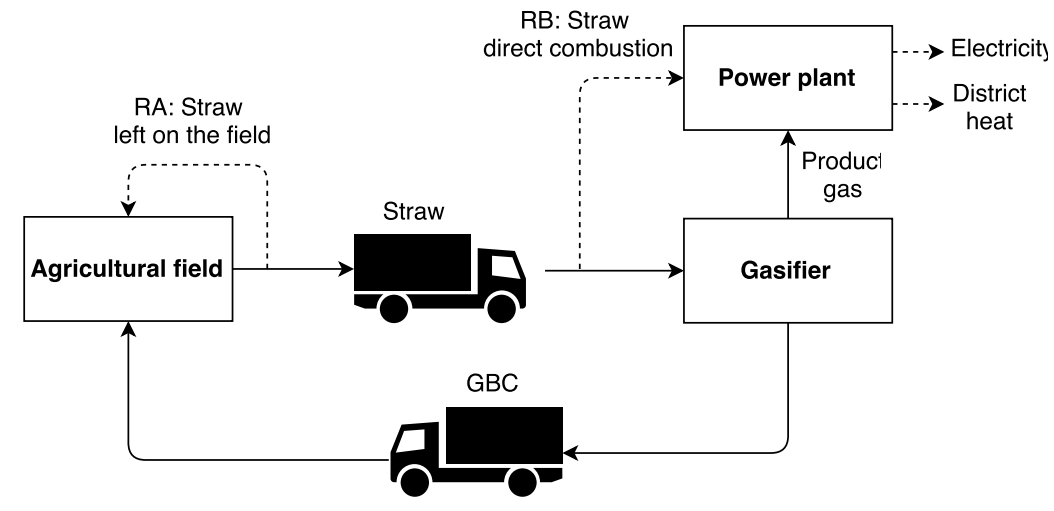

Figure 1: Integrated bioenergy and agriculture system schematic

are calculated based on the residue harvest index (0.42), i.e. ratio between total residues and total harvest, while the straw part of the total residues was estimated to be $65 \%$. The residues left on the field (referred to as residues) are equal to the total residues for RA, and equal to the difference between the total residues and the straw for RB and S1S3. Ultimate analysis of the residues and straw was taken from Vassilev et al. [21] and the lower heating value (LHV) from Nguyen et al. [15]. Straw is then transported $20 \mathrm{~km}$ to the energy system where it is either directly combusted for heat and power generation or gasified at specific carbon conversion before the product gas can be combusted, the GBC or bottom ash is transported back to the same agricultural field $20 \mathrm{~km}$ away from the energy system.

${ }^{1}$ Carbon conversion in the gasifier is the carbon ratio between fuel input and product gas out of the gasifier, the rest leaves the gasifier as biochar. 


\subsection{Analytical Approach}

The analysis follows the framework of consequential LCA. The fertilization and field emissions were modelled by a nutrient balance based on inputs, what is harvested and the emissions that occur as a consequence. Other factors in the LCA, except for transportation between the field and the gasifier, were modelled with the aid of the Ecoinvent 3.1 database [22], i.e. the work processes, pesticides input, farm transport and seeds input. The Ecoinvent database was also used for all upstream processes. The analysis was made from cradle to gate for two functional units.

\section{Functional units.}

1) $\mathrm{kg}$ of grain produced, to show the effect of wheat straw utilization in reference to the primary product of agricultural field.

2) $\mathrm{kWh}$ of electricity produced, to show the effect of using wheat straw as a fuel in an energy system in reference to alternative resources.

The amount of carbon and the state of it is expected to have a significant effect on the nitrogen dynamics, as noted in Nguyen at al [16]. Most changes are expected in the nitrogen build-up which affects the nitrogen leaching potential.. The change in nitrogen balance was modelled for two cases. Case 1 regulates the nitrogen changes with the mineral fertilizer and constant yield, and Case 2 regulates the changes with the mineral fertilizer increase per decrease in nitrate leaching and vice versa. Which subsequently effects the yield, guidelines from the agricultural and fisheries ministry of Denmark were followed for yield impact from increase or decease in nitrogen fertilization [23]. Carbon soil sequestration potential was calculated by detail simulation of the atmospheric load of carbon emission from organic inputs to the agricultural soil, following the principles from Petersen et al [8].

A computer model was made to calculate the LCA of the combined agricultural and bioenergy system. The model consists of blocks where the first one is a definition of the chemical composition of the residual and main product. This then connects to interconnected blocks of nutrient balance, soil carbon simulation, energy system model and the Ecoinvent 3.1 database [22]. The resulting life cycle inventory (LCI) is passed to the LCA with the 2013 IPCC 100 year global warming potential [24] life cycle impact assessment (LCIA) method. The basic flow of the model is displayed in Figure 2. The model is implemented in Python and is built on top of three freewares, i.e. Dynamic Network

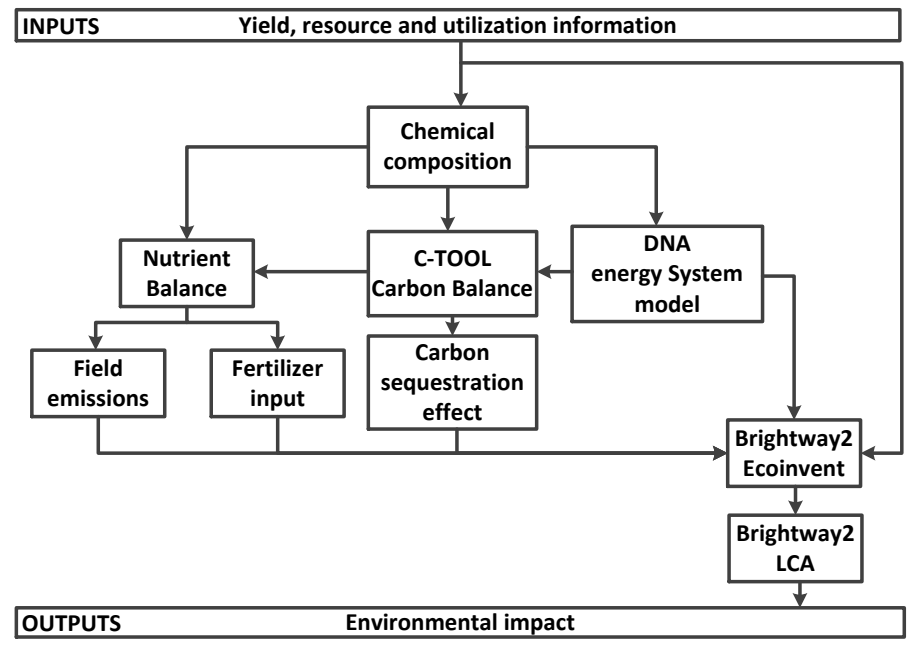

Figure 2: Python system model.

Analysis (DNA) for energy system modeling [19], C-TOOL for soil carbon simulation [17], [18] and Brightway2 for Ecoinvent 3.1 database communication and LCA processing [20]. 


\subsection{Agricultural System}

The production is assumed to take place in Zealand Denmark, where the average high temperature during summer is $15.7^{\circ} \mathrm{C}$ and the average low temperature during winter is $0.1^{\circ} \mathrm{C}$ [25]. The rain fall is estimated to be $760 \mathrm{~mm} /$ year [25] and the soil is assumed to have a clay content of $12 \%$ and $2 \%$ soil organic carbon in the top soil. Nitrogen in organic matter is then calculated based on: 1. the soil organic carbon value, 2. the total soil nitrogen, 3. soil carbon and nitrogen ratio, 4 . the ratio between nitrogen in organic matter and total soil nitrogen and 5 . the soil volume and bulk density [26].

\subsubsection{Nutrient Balance}

The average nutrient ratio between grain and straw from the Phyllis2 database [27] was used to calculate the macro nutrients, i.e. nitrogen, phosphorus and potassium (NPK), of the grain for the nutrient balance. In the Phyllis2 database the NPK of the grain is on average $70 \%, 75 \%$ and $25 \%$ of the whole crop (grain + straw) for nitrogen, phosphorus and potassium, respectively.

The nutrient balance model is based on conservation of mass and is restricted to the major macro nutrients, i.e. nitrogen, phosphorus and potassium. The model has the assumption that the net annual change of mass contained within the system is assumed zero for phosphorus $(\mathrm{P})$ and potassium $(\mathrm{K})$. This means that the inputs, i.e. $\mathrm{P}$ and $\mathrm{K}$ mineral fertilizer, are set to match the outputs. However nitrogen is modelled to both mineralize and accumulate in the soil, which affects the required input of nitrogen fertilizer in Case 1 and the yield in Case 2.

The phosphorus and potassium balances in the model are based on the uptake by the harvested products, i.e. grains and straws (if harvested), and the amount of emissions associated with these macro-nutrients. Phosphorus outputs through emissions were assumed based on a factor estimating the combined leaching and surface run-off of the nutrient according to Hauschild and Potting [28]. The potassium emissions are calculated based on a method recommended by Food and Agriculture Organization (FAO) in their Assessment of nutrient balance: Approaches and Methodologies [29]. Which estimates leaching by a regression model from an extensive literature research, valid for a wide range of soils and climates, adopted from DeWilligen [30] and his developed nitrogen leaching regression model. That model is based on annual precipitation, fertilizer input and the soil's cation exchange capacity.

The nitrogen balance includes deposition, precipitation, and biological fixation based on P. H. Nielsen et al. [31]. Moreover, mineralization and accumulation of nitrogen are included in the model, where the build-up is modelled to follow the build-up of soil organic carbon, given in Section 2.3.2. Nitrous oxide emissions were estimated based on IPCC recommendations and include both direct and indirect emissions [32]. The direct emissions are calculated as a percentage of the total nitrogen, i.e. mineral and biological fertilizer, and crop residues, added to the field from the harvest of the preceding crop to the harvest of the present crop. Indirect emissions include a certain percentage of emissions originally emitted as $\mathrm{NH}_{3}$ and $\mathrm{NO}_{3}^{-}$, which soon thereafter converts to $\mathrm{N}_{2} \mathrm{O}$. The $\mathrm{NH}_{3}$ emission was estimated based on Asman [33] for the nitrogen fertilizer assumed and the nitrate leaching $\mathrm{NO}_{3}^{-}$was calculated using the SQCB- $\mathrm{N}_{2} \mathrm{O}$ model [34] with the appropriate parameters for the considered area.

The nutrients within the straw are assumed to be $100 \%$ utilized with respect to phosphorous and potassium, and 30\% for nitrogen. This is in line with the assumptions of Nguyen et al [15] and Parajuli er al. [7]. The marginal mineral fertilizer used in this assessment are based on the market of fertilizer for NPK in Ecoinvent 3.1 [22]..

\subsubsection{Carbon Soil Sequestration Effect}

The carbon captured by the crop which will eventually be released to the atmosphere, i.e. from carbon decay in soil and/or combustion in the power plant. The carbon soil sequestration effect is the GWP effect of introducing the soil as a carbon sink for atmospheric carbon through carbon capture by the total residues and subsequent sequestration in the soil with the residues and GBC.

Radiative forcing (RF) is a measure of the capacity of a substance, e.g. a gas, to affect the energy balance controlling the Earth's surface temperature, expressed in $\mathrm{W} / \mathrm{m}^{2}$. Integrated $\mathrm{RF}$ is thus a measure of the energy that is added to 
the system during a chosen time horizon due to release of the substance. The global warming potential (GWP) is an environmental indicator that uses integrated RF to predict the effects of releasing a substance to the atmosphere on global warming, and benchmarks all substances to carbon dioxide. It is thus well suited to use the method of Petersen et al [8] to calculate the effect of storing the carbon in the soil instead of in the atmosphere as $\mathrm{CO}_{2}$. This is in line with the biogenic GWP calculation of Cherubini et al. [35,9] for wood sourced bioenergy.

The method is based on using the Bern carbon cycle model $[36,37]$ to describe the decay of carbon in the atmosphere over a specific time horizon. The carbon in the atmosphere decays as it is absorbed by the many sinks in Earth's system, e.g. oceans, forests.

$$
\begin{gathered}
y(t)=A_{0}+\sum_{i=1}^{3} A_{i} e^{-t / \tau_{i}} \\
A_{T}=\int_{1}^{T} y(t)
\end{gathered}
$$

Where $A_{0}=0.217, A_{1}=0.259, A_{2}=0.338, A_{3}=0.186, \tau_{1}=172.9, \tau_{2}=18.51, \tau_{3}=1.186, t=$ specific time and $T=$ time horizon. Moreover $A_{T}$ is the time-integrated mass load of CO2 in the atmosphere in a specific time perspective. Further, the method includes the decay of carbon input in soil, simulated by C-TOOL, which simulates the development of soil carbon content, and can track specific carbon inputs at any desired time span. This enables the atmospheric decay of the released $\mathrm{CO} 2$ from carbon decay in the soil $\left(S_{T}\right)$ to be calculated.

$$
\begin{gathered}
S_{T}=\sum_{i=1}^{T}\left(a(i) \sum_{j=1}^{T-i} y(j)\right) \\
R_{T}=\frac{A_{T}-S_{T}}{A_{T}}
\end{gathered}
$$

$R_{T}$ is the ratio between the carbon stored in the natural sinks, i.e. soil, oceans, forests, etc..., and carbon stored in the atmosphere as $\mathrm{CO}_{2}$. The time horizon used is set to match the impact indicator, i.e. 100 years. The carbon in the residues and the GBC have very different characteristics, making the decay in soil very different as well, as the carbon in the residues decays much more rapidly than the carbon in the GBC after thermal treatment in the gasifier.

\subsubsection{Ecoinvent Processes}

The Life Cycle Inventory (LCI) data of the inputs and upstream processes connected to the wheat grain production are based on average values from seven wheat grain production LCA's given in the Ecoinvent database [22].

The seeds were assumed to be botanic and cultivated in the same way as the wheat grain with some additional processes, such as transportation to processing, the processing itself, storage and finally transportation to a regional storehouse [38].

For the impact of the pesticides, the active ingredient is found and paired with the classification of a pesticide substance specified in Green [39] and Bhat et al. [40] according to Hartley and Kidd [41] and Tomlin [42], as adopted by Ecoinvent.

The work processes includes all operations, except transportation on the wheat field, during one year of wheat production. The inclusion of baling and loading of the bales is accounted for where appropriate. The machinery and their fuel usage are included in the field operations.

\subsection{Transportation}

For every input to the agricultural field where LCI data was collected from Ecoinvent, it was assumed that it would be transported from a regional storehouse. It was further assumed that the average distance between the wheat field and the regional storehouse is $20 \mathrm{~km}$. The same assumption was applied for transportation of residues and GBC between the field and gasifier. Moreover, the large volume/weight ratio of the straw bales were accounted for by increasing the number of trips required based on the volume available in the lorries. 


\subsection{Energy System}

The LT-CFB is a Low Temperature Circulating Fluidized Bed (LT-CFB) gasifier, designed to handle biomass with high ash content like wheat straw. The low operating temperature of the gasifier alleviates the problems caused by sintering of the ash, such as fouling from potassium and corrosion from chlorine, as the ash leaves the gasifier in solid form [3].

However, a drawback of the gasifier is that the gas produced has very high content of tar and particles, rendering it presently unsuitable for direct use in a gas engine for electricity production and for synthesis to biofuels [3]. Nevertheless, it can be combusted and used to fuel a steam power plant.

Most of the nutrients that were removed with the straw are contained in the straw ash after gasification and because the ash is in solid form, the nutrients and carbon can be returned back to the field.

The carbon content of the ash or GBC can be changed by changing the design or the operation of the gasifier. In this way more carbon can be kept in the GBC, which increases the carbon soil sequestration and thus has a significant effect on the GWP of the system. The distribution of carbon to biochar and product gas is controlled by the carbon conversion factor (CC). CC describes the ratio of carbon in the energy resource that is gasified to product gas, the rest of the carbon is biochar. To find the lowest CC the energy system was simulated by varying the $\mathrm{CC}$ towards zero or when no heat or power could be produced.

The energy system assumed in this analysis consists of a LT-CFB gasifier which is connected to a conventional steam power plant. In the power plant the product gas is burned to produce electricity and heat. The efficiencies of the gasifier and the subsequent conversion to electricity and heat is taken from primary data of a pilot plant [16].

For the power and heat generation in the total system, the analysis accounts for substituted technologies and accredits the impacts that are avoided by the substitution to the system. The produced electricity is assumed to replace the marginal electricity technology in Denmark, which is a composition of coal, natural gas and wind, with the ratios, $0.48,0.51$ and 0.01 respectively [13]. The heat produced is assumed to substitute the heat production of a specific technology, which is assumed to be a decentral biomass based combined heat and power plant. The reason for the difference in the substituted technologies is that the electricity produced will be connected to the national grid, and thus affect the marginal of that grid, but the heat produced is connected to the local district heating network which in this case is assumed to be a biomass CHP plant. In the sensitivity analysis in Section 2.6 the effects of the substituted technology choices are analysed.

\subsection{Sensitivity Analysis}

To test the results a sensitivity analysis was performed. The most uncertain aspects of the analysis connected to its objective, are the biochar carbon decay in soil and its soil sequestration effect. and nitrogen build-up with carbon sequestration. Although there are indications that the assumptions made for the decay of GBC carbon are reasonable [14], modelling the system with different decay end states can indicate how strong the results of the carbon soil sequestration effect are. A question raised by Nguyen et al. [16], is whether or not the stability of the carbon in the GBC changes by changing the carbon conversion factor of the gasifier. Connected to the carbon decay in soil is the nitrogen build-up, where the longterm nitrogen build-up is assumed 1:10 of the carbon build-up [43]. These parameters were analysed for their effect on the final results.

It is also interesting to take closer look at the change in energy efficiency and increase in carbon soil sequestration by changing the CC. Decreased energy efficiency of the gasifier will decrease the electricity and heat produced and thus decrease the substituted marginal electricity and district heating by the system. The difference between what is gained by the carbon soil sequestration increase and what is lost by the gasifier energy efficiency decrease can be observed in the LCA results. However, what if the marginal electricity is different then what was assumed or what if a specific energy resource is substituted rather than the marginal, and what if the energy resource used in the distric heating system is different then what is assumed. How will that change the results with respect to the best CC practice. To find that out other electricity and district heating sources are substituted and the change in GWP per change in CC is compared to the GWP per CC change or the carbon soil sequestration. 


\section{Results}

Below the carbon soil sequestration effect for the scenarios is presented, and the LCA results of the integrated bioenergy and agriculture system scenarios for the different cases is given and explained in detail.

\subsection{Gasifier carbon conversion}

The energy system was simulated in DNA, to get the lowest possible CC for S3. Figure 3 displays the result of this simulation in terms of the efficiency of the electricity and district heat production, and fuel utilization. It can

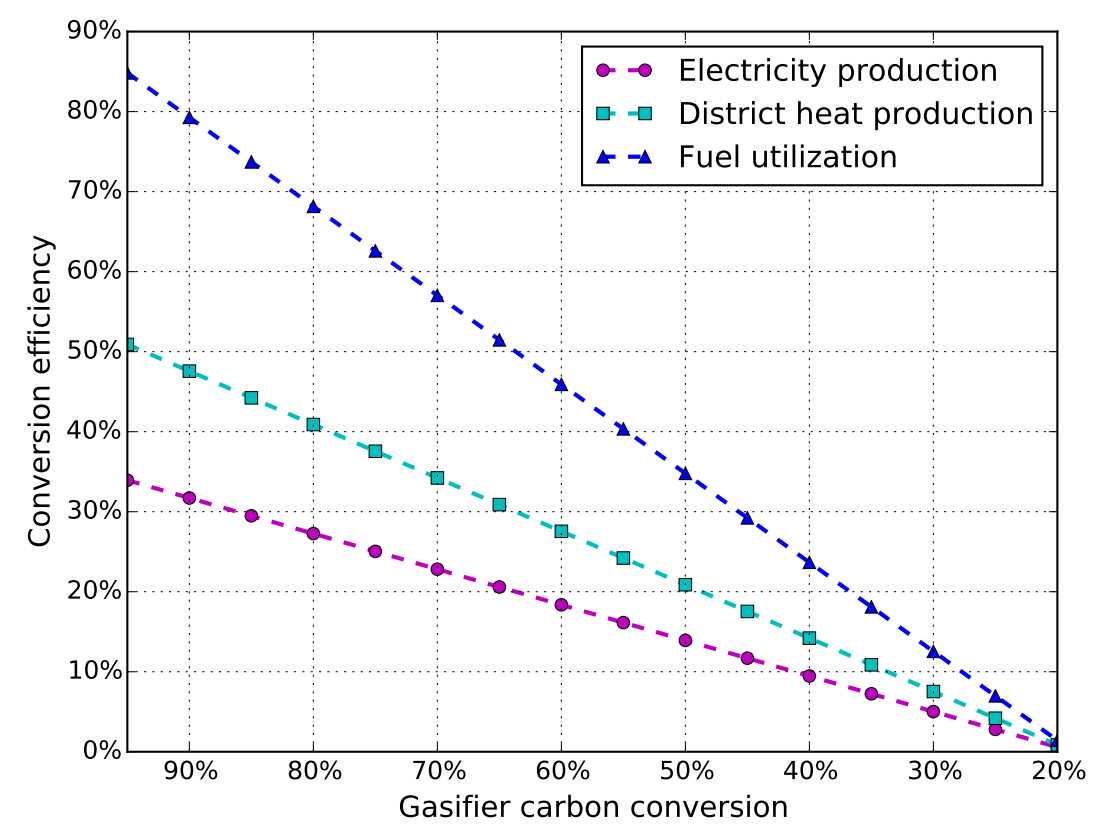

Figure 3: Distribution of Carbon in the atmosphere and sinks

be seen in Figure 3 that no heat or power generation is beyond 20\% carbon conversion, making the CC for the low $\mathrm{CC}$ scenario equal to 0.2 . Further carbon conversion reduction could possibly be achieved in a dedicated pyrolyzer operating at lower temperatures. However, carbon emission can be expected that will decrease the carbon content of the GBC

\subsection{Carbon Soil Sequestration Effect}

The decay of carbon which is added to the soil is displayed over a 100 year horizon in Figure 4 for the different scenarios and normalized to the carbon input. In the legend of the figure, numerical values of carbon still retained in the soil at the 100th year end state is given for all scenarios. Additionally as a reference, GBC input to soil is included.

It can be seen that for the residues that there is much faster decay in the first years and that $1.2 \%$ of the original carbon remains in the soil when 100 years have passed. However, the High and Low CC scenarios show as expected that more carbon in the GBC increases the carbon sequestered over a 100 year horizon, 3.2 and $44.9 \%$ for S1 and S3, respectively. This is because carbon in GBC after thermal treatment in the gasifier is much more stable in soil then before the treatment, i.e. does not decay to the same extent, which is displayed in the figure by the difference between residue and carbon in GBC decay curves in the figure. 


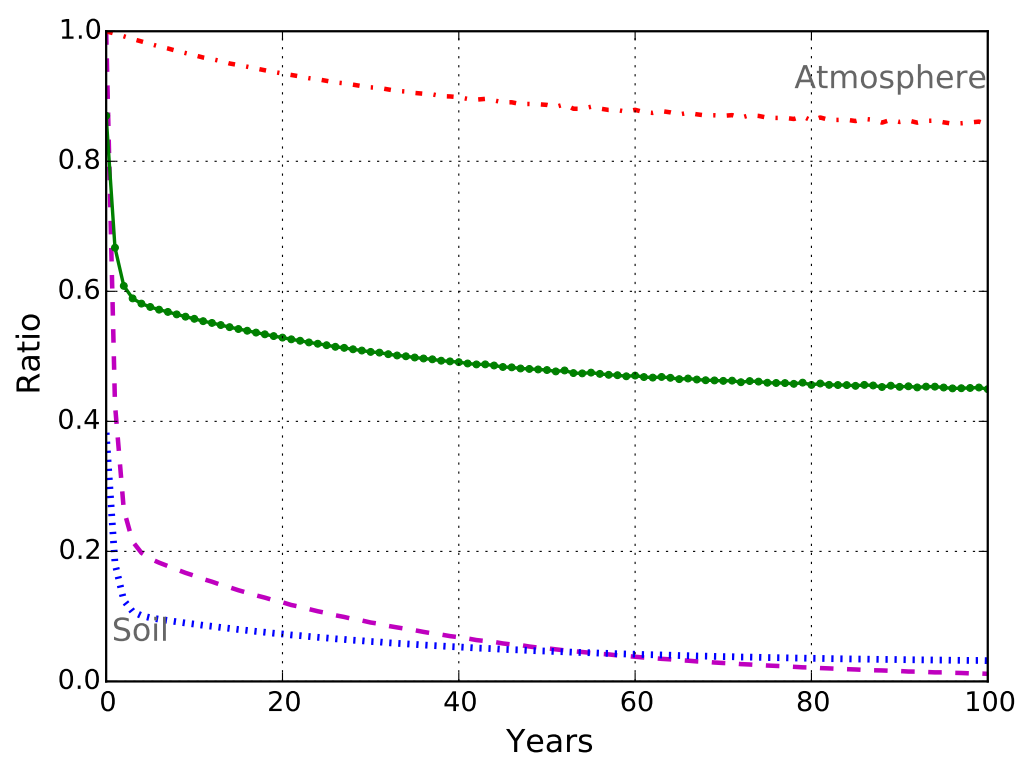

\begin{tabular}{|llll|}
\hline-- & Reference $\left[\mathrm{C}_{\text {end }}=1.2 \%\right]$ & $\ldots$ & High CC $\left[\mathrm{C}_{\text {end }}=3.2 \%\right]$ \\
$\cdots$ & $\mathrm{GBC}\left[\mathrm{C}_{\text {end }}=85.7 \%\right]$ & $\longrightarrow$ & Low CC $\left[\mathrm{C}_{\text {end }}=44.9 \%\right]$ \\
\hline
\end{tabular}

Figure 4: Carbon decay.

Figure 5 displays the distribution of the carbon between atmosphere and sinks over a 100 year period. The carbon soil sequestration effect of a specific scenario is equal to the area between the curve of the scenario and the curve of the Bern carbon cycle ${ }^{2}$ (representing the decay of carbon in the atmosphere), which is equal to the difference in the integrated radiative forcing between a pulse emission and the scenarios analysed for the fate of carbon. In the legend of the figure, numerical values for the percentage carbon bound in sinks are given.

\subsection{Life Cycle Inventory Analysis}

For Case 1 the results of the LCI are given in Table 1. Only resulting inventory data that were not acquired as averages from the Ecoinvent database are shown. These results correspond to the parts of the system that are of the most importance and interest, i.e. fertilization, field emissions, carbon soil sequestration, transportation and energy generation. When comparing S1 - S3 it can be seen that transportation and the carbon soil input increase with decreased CC in the gasifier. This was to be expected as more carbon is in the GBC and thus more weight and amount transported back to the field and incorporated into the soil. What is also worth noting is the change in fertilization.

Nitrogen fertilization increases when straws are removed, but is mitigated by retuning the GBC. The reason for this is that by practicing straw removal, the nitrogen in the straws cannot be mineralized in the soil and used by the plants on the field with time, and by gasifying the straws the nitrogen within them will end up in the gas phase and not be available in the GBC on their return to the soil. However, by increasing the carbon in the GBC, i.e. lowering the CC in the gasifier, and returning to the field, carbon will build up in the soil which was modelled to effect the build up of nitrogen in the soil, see Section 2.3.1. With more nitrogen in the soil, less fertilizer is required for the same yield with time as nitrogen becomes available to the plant as it is mineralized.

\footnotetext{
${ }^{2}$ The Bern Carbon Cycle $\mathrm{CO}_{2}$ decay in the atmosphere can be observed in the figure, this would be the decay of the $\mathrm{CO}_{2}$ in the atmosphere if it was never captured by the total residues.
} 


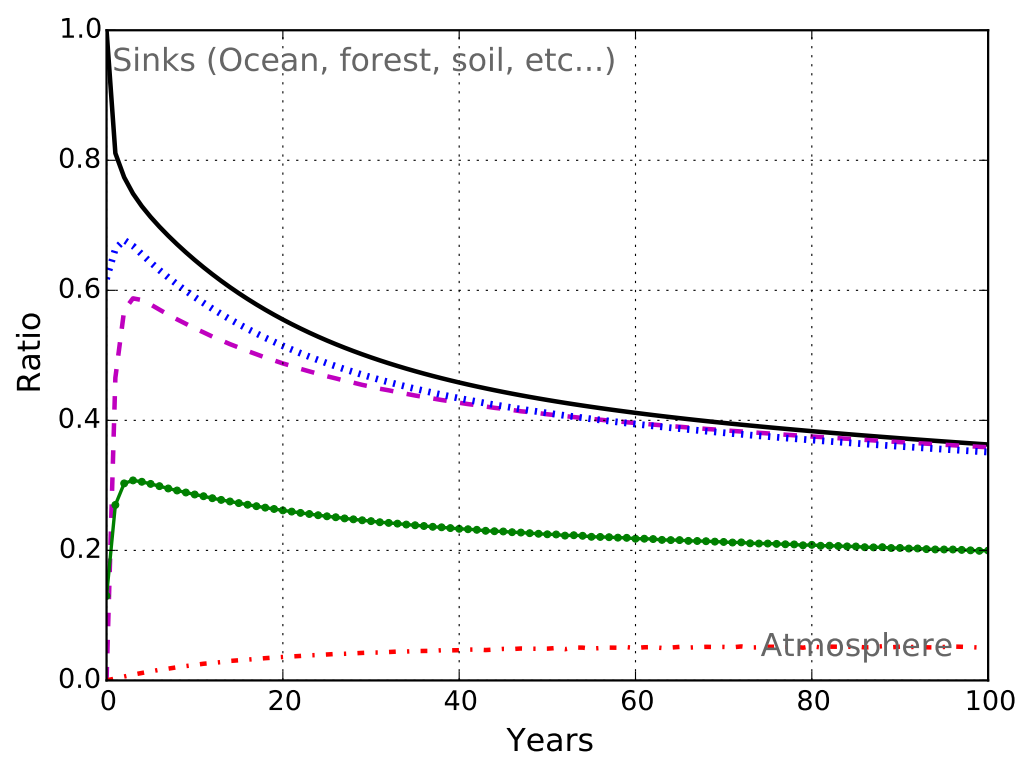

$$
\begin{array}{llll}
- & \text { Pulse emissions } & \cdots \cdots & \text { High CC }[R T=6.7 \%] \\
-- & \text { Reference }[R T=10.9 \%] & \longrightarrow & \text { Low CC }[R T=51.0 \%] \\
\cdots & \text { GBC }[R T=91.0 \%] & & \\
\hline
\end{array}
$$

Figure 5: Distribution of Carbon in the atmosphere and sinks

Table 1: Life Cycle Inventory, CASE 1.

\begin{tabular}{l|ccccc} 
& $\mathrm{RA}$ & $\mathrm{RB}$ & $\mathrm{S} 1$ & $\mathrm{~S} 2$ & $\mathrm{~S} 3$ \\
\hline Grain yield $[\mathrm{kg}]$ & 8000.0 & 8000.0 & 8000.0 & 8000.0 & 8000.0 \\
Straw harvested [kg] & 6103.8 & 6103.8 & 6103.8 & 6103.8 & 6103.8 \\
Straw harvested [GJ (LHV)] & 88.5 & 88.5 & 88.5 & 88.5 & 88.5 \\
Transportation off field [tonne $\cdot \mathrm{km}$ ] & 0.0 & 164.1 & 167.9 & 173.1 & 210.1 \\
$\mathrm{~N}$ fertilizer [kg nitrogen] & 148.1 & 164.4 & 162.5 & 158.7 & 131.9 \\
$\mathrm{P}$ fertilizer [kg diphosphorus pentaoxide] & 31.0 & 31.7 & 31.4 & 31.4 & 31.4 \\
$\mathrm{~K}$ fertilizer [kg potassium oxide] & 55.9 & 65.8 & 61.4 & 61.4 & 61.4 \\
$\mathrm{~N}_{2} \mathrm{O}$ emission [kg dinitrogen monoxide] & 3.9 & 4.0 & 4.0 & 3.9 & 3.6 \\
Carbon sequestration effect [kg carbon] & 498.3 & 184.6 & 302.5 & 541.1 & 2224.7 \\
Electricity production [MWh] & 0.0 & 5.5 & 8.3 & 7.3 & 0.1 \\
Heat production [GJ] & 0.0 & 52.9 & 45.1 & 39.6 & 0.8
\end{tabular}

This is different for phosphorus and potassium fertilization. However, like for nitrogen above, phosphorus and potassium are removed with the straws, but unlike nitrogen, phosphorus and potassium are concentrated in the GBC after gasification and are modelled to return to the field with $95 \%$ efficiency and $100 \%$ mineral fertilizer substitution value, see Section 2.3.1.

The Life Cycle Inventory for Case 2 is given in Table 2 in the same way as above for Case 1. From Table 2 it can be seen that the yield increases with more carbon inputs to the soil as more nitrogen fertilization is allowed with lowered nitrate leaching. The greater the yield, the greater the electricity and heat production, transportation and carbon soil sequestration effect, as more straws are available. This is different from what was seen in the results for Case 1 . When comparing the LCI results for the two cases, differences are visible in all categories. All of which are effected by the 
Table 2: Life Cycle Inventory, CASE 2.

\begin{tabular}{l|ccccc} 
& $\mathrm{RA}$ & $\mathrm{RB}$ & $\mathrm{S} 1$ & $\mathrm{~S} 2$ & $\mathrm{~S} 3$ \\
\hline Grain yield [kg] & 9452.2 & 8200.3 & 8344.8 & 8806.5 & 10699.1 \\
Straw harvested [kg] & 7211.8 & 6256.7 & 6366.9 & 6719.2 & 8163.1 \\
Straw harvested [GJ $(\mathrm{LHV})]$ & 104.6 & 90.7 & 92.3 & 97.4 & 118.4 \\
Transportation off field [tonne $\cdot \mathrm{km}$ ] & 0.0 & 167.3 & 177.7 & 204.6 & 324.6 \\
$\mathrm{~N}$ fertilizer [kg nitrogen] & 181.0 & 172.2 & 176.0 & 188.0 & 237.2 \\
$\mathrm{P}$ fertilizer [kg diphosphorus pentaoxide] & 31.2 & 31.8 & 31.5 & 31.5 & 31.8 \\
$\mathrm{~K}$ fertilizer [kg potassium oxide] & 55.9 & 66.1 & 61.6 & 61.9 & 63.2 \\
$\mathrm{~N}_{2} \mathrm{O}$ emission [kg dinitrogen monoxide] & 4.7 & 4.2 & 4.3 & 4.6 & 6.0 \\
Carbon sequestration effect [kg carbon] & 588.7 & 189.6 & 315.6 & 748.0 & 2975.2 \\
Electricity production [MWh] & 0.0 & 5.6 & 8.7 & 7.4 & 0.2 \\
Heat production [GJ] & 0.0 & 54.2 & 47.0 & 40.0 & 1.0
\end{tabular}

yield difference between the cases.

\subsection{Life Cycle Impact Assessment}

Figures $6 \mathrm{a}$ and $6 \mathrm{~b}$ display the result of the consequential LCIA analysis with kg grains produced as its functional unit for cases 1 and 2, respectively. The system expansion covers the conversion of the straws in the energy system through the Pyroneer and a CHP plant for electricity and heat production, along with return of the GBC with varying carbon content with different CC values. Reference is given to wheat grain production with no straw removal and thus no heat and power production.

It can be seen in the figures that removing the straws and using them in an energy system, substituting the marginal energy sources gives better result in terms of IPCC 2013 GWP 100 than leaving them on the field. Also visible in the figures are the changes between the S1 - S3, the effects of carbon soil sequestration is greater than substituting marginal electricity and district heating. Comparing the results of the two cases it can be seen that Case 2 performs batter than Case 1, as it is accredited the substitution of another wheat grain production. As with increased yield more heat and power can be produced, and more carbon can be incorporated to the soil with the GBC.

Figures $7 \mathrm{a}$ and $7 \mathrm{~b}$ display the results of the consequential LCIA analysis with kWh electricity produced as its functional unit, i.e. independent of the substituted electricity production, for cases 1 and 2, respectively. The input of the straws to the energy system is modelled using the cut-off allocation from the grains, i.e. only the direct and indirect impacts of removing the straws are allocated to them. The system expansion includes the retuning of the GBC with varying carbon content to the field.

It can be seen in the figures that lowering the $\mathrm{CC}$ give better results, like we observed in Figures $6 \mathrm{a}$ and $6 \mathrm{~b}$. Moreover, like above we can see that the changes are greatest for the carbon soil input effect, while other changes between the scenarios are less. From Table 2 it can be seen that the increase in yield is about more for S3 but compared to RA and S1 has less yield but less mineral fertilization. This has a negative effect on the environmental impact for both scenarios as the lower fertilization in S1 has less effect than lower yield.

Figure 8 gives the results displayed in Figures $7 \mathrm{a}$ and $7 \mathrm{~b}$ by comparison to the total LCA score of utilization of alternative energy resources.

It can be seen in the figure that using wheat straws in an integrated bioenergy and agriculture system can outperform all other major energy sources in terms of GWP if the right CC is used. To be climate neutral or even climate friendly, the CC will need to be below 0.86 and 0.81 for cases 1 and 2, respectively. 


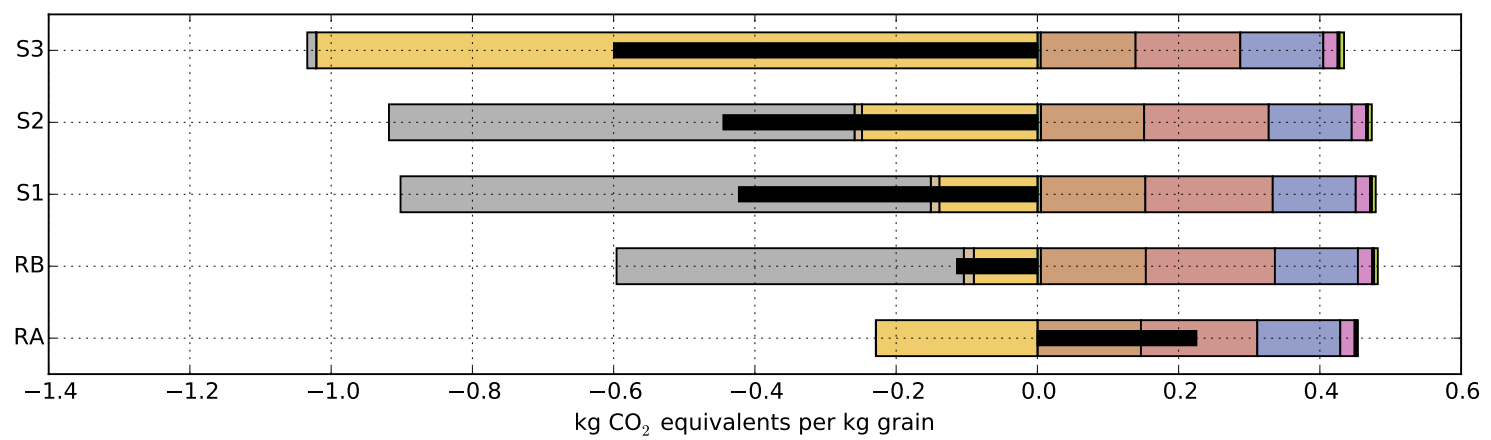

(a) CASE 1 .

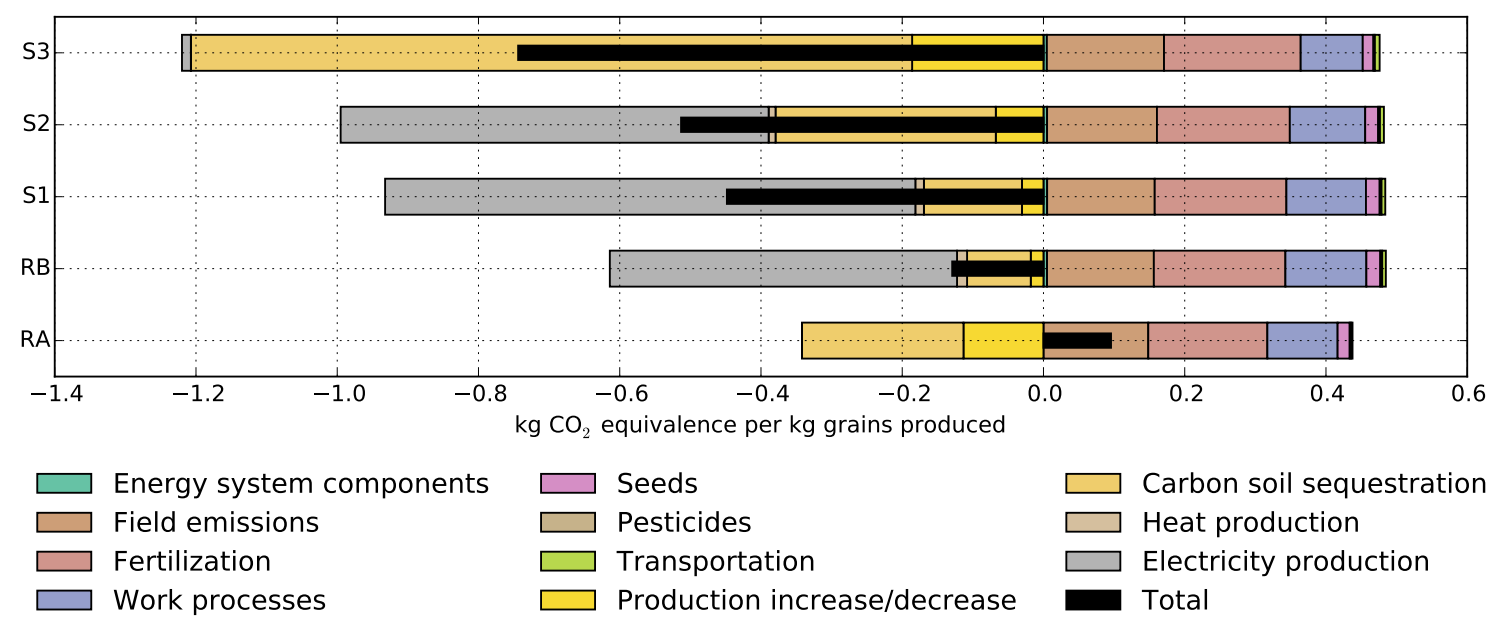

(b) CASE 2 .

Figure 6: LCIA result for both cases with functional unit kg grains produced.

\subsection{Sensitivity Analysis}

The carbon sequestration effect and nitrogen build-up were varied to test the robustness of the results. As found in the results above maximum biochar production is better then maximum heat and power production in terms of climate change impact. The carbon sequestration effect can decrease by $18 \%$ (case 1) or 19\% (case 2) for that results to hold. However, for both case 1 and 2 a change in nitrogen build-up cannot effect the outcome of that result.

In Figure 9 the results of the analysis on the effect of changing the substituted electricity and district heating, is displayed. On the y-axis different district heating system are substituted by the CHP plant heating part of the integrated bioenergy and agricultural system. Electricity substituted corresponding to the components of the marginal electricity composition in the Danish energy system, i.e. coal based, natural gas base and wind electricity generation. If the scatter dot is in the left side of the red line (representing the GBC carbon GWP change per CC change), that indicates that it is better to maximize biochar production. However, of the bars end at the right side of the red line, it is better to maximize $\mathrm{CC}$.

It can be seen in the figures above that if the district heating substituted is by any of the systems analysed here, it always better to maximize biochar production for Case 2 . In case 1 , for the two biomass fuelled district heating it is better maximize biochar production, except when coal fuelled electricity system is substituted. However if the district heating substitutes fossil fuel based production, maximum energy generation should be the preferred optionm except when both district heating and electricity technologies substituted are fuelled with natural gas. 


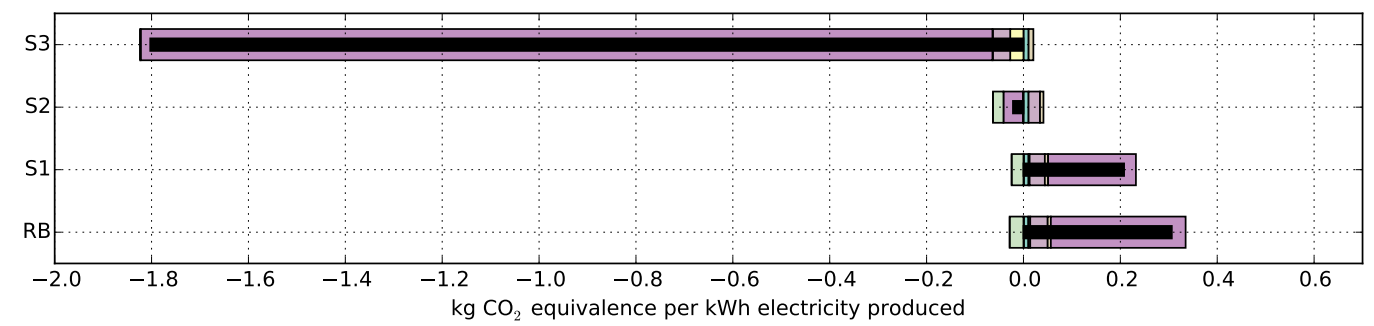

(a) CASE 1 .

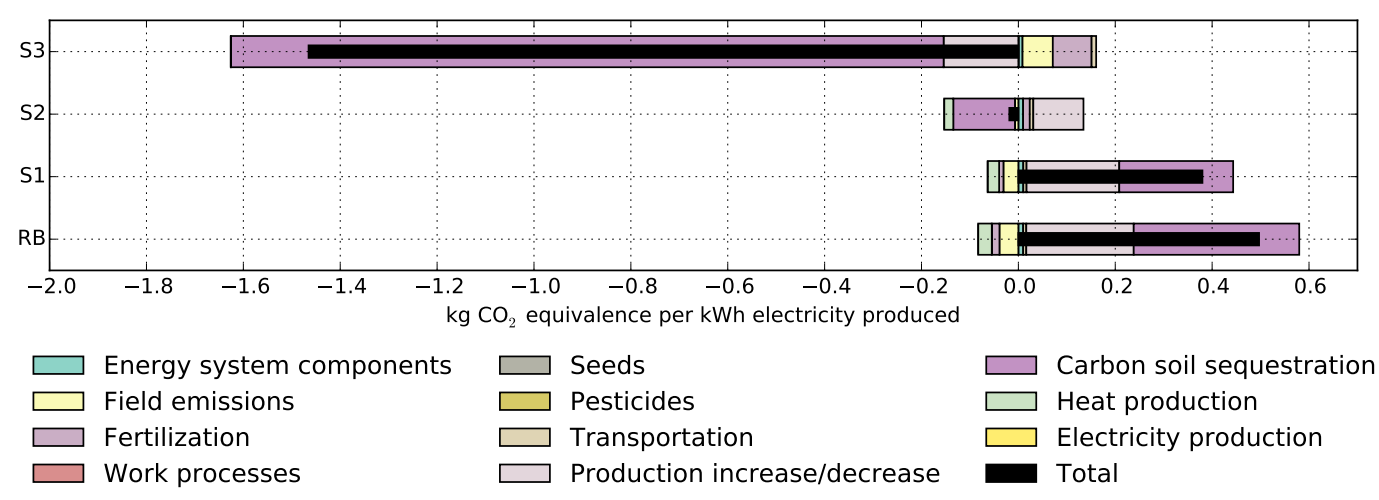

(b) CASE 2.

Figure 7: LCIA result for both cases with functional unit kWh electricity produced.

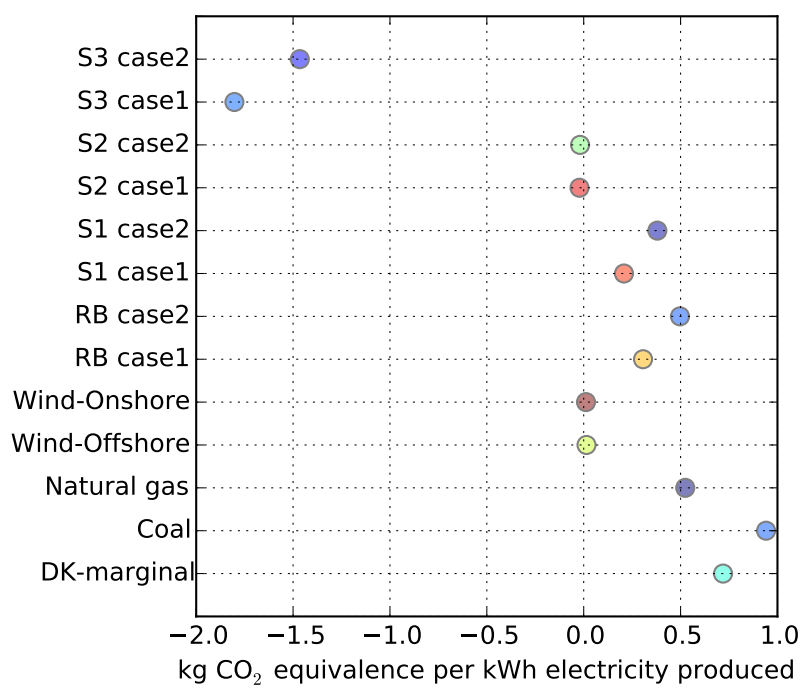

Figure 8: Result of the straw utilization in reference to alternative resource utilization.

\section{Discussion}

In this type of analysis a 100 year time horizon is the most common, second to that is the 20 year horizon. However, according to IPCC the current global emissions from the energy and industrial sectors have the largest contribution to warming for a 100 year horizon. Conversely the agricultural sector is said to have the largest contribution to warming 


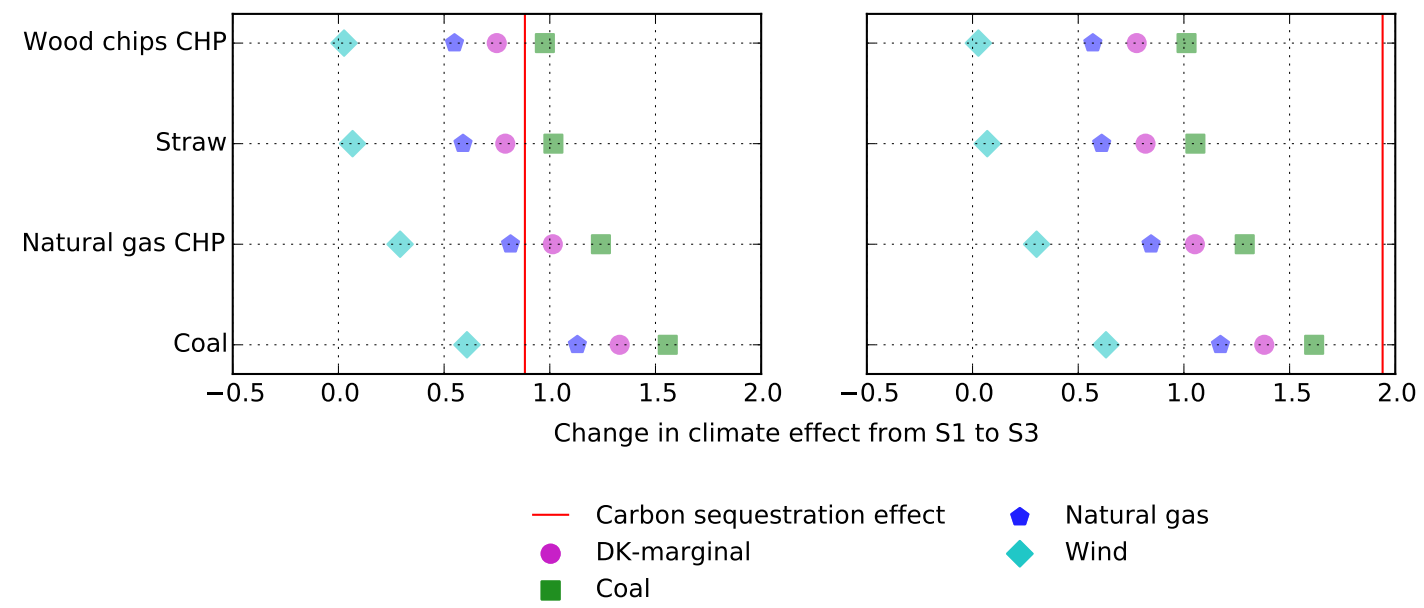

Figure 9: Sensitivity analysis for cases 1 and 2, Low CC scenario.

for 20 year horizon. The reason for that is the $\mathrm{CH}_{4}$ part of the emissions as its lifetime in the atmosphere is relatively short. Despite that, the main gas contributors in the agricultural system analysed in this research are $\mathrm{CO}_{2}$ and $\mathrm{N}_{2} \mathrm{O}$, both of which have increasing contribution over time but stabilize in around 20 years when looking at the 100 year time horizon [24]. This can mean that because no significant short-lived gases are emitted to the atmosphere, the 100 year time horizons analysis is appropriate.

When observing the results of the two cases it is obvious that the carbon soil sequestration effect and substituted electricity production are dominant. However, what is striking is that increasing the carbon in the GBC at the cost of the energy efficiency of the gasifier has positive effect on decrease of the global warming potential. This is the case both when looking at it from the agricultural system (per kg grain) perspective and from the energy system perspective (per kWh electricity). For Case 2, this is even more evident than in Case 1 as the yield increase by added nitrogen fertilization with lowered nitrate leaching is better than decreasing nitrogen fertilization for constant yield.

In the sensitivity analysis the GBC stability was varied to show how an increase in decay with CC decrease would affect the total results. Despite including that in the analysis it is not expected to change by changing the carbon conversion to $80-86 \%$ for a climate neutral resource as long as the pyrolysis phase of the gasifier is fully completed and is independent of the $\mathrm{CC}$ change in the gasification phase, which could be the case for the Pyroneer gasifier. However, although the Low CC scenario assumes CC of $20 \%$ the gasifier must be analysed for the Lowest CC an yet a full pyrolyses operation, to ensure maximum stability in the soil. Moreover, in the sensitivity analysis of the substituted products it was demonstrated that great care must be taken when deciding on the best CC which strongly depends on what is substituted in the consequential LCA analysis.

What was not included in the modelling is the change in the soil's water retention for the different scenarios. This is expected to occur, and it would lower necessary nitrogen supply to the field in Case 1 and increase the yield in Case 2 as even less nitrogen would be leached from the soil. Both of these would contribute in favour of returning more GBC to the field and decreasing the CC.

It would be interesting to expand the analysis to include more environmental impacts and economic impact of decreased CC. To further establish the system as an environmental impact mitigating technology other impact factors should be analysed, e.g. eutrophication, ecotoxicity and non-renewable resource demand. For this recycling of nutrients, heavy metal accumulation and the possible decrease in nitrate leaching would be of special notice.

It could be that lowering the $\mathrm{CC}$ would increase the value of the fertile $\mathrm{GBC}$ and thus mitigate the revenue losses from decreased efficiency. Additionally, a gasifer with a low CC could be smaller and it is expected that for the same input the investment cost would be less. However, the revenues from electricity and district heat sales would be less also, but the GBC could be worth more with increased biochar content. It would be interesting to do an economics analysis 
to fully judge the economics of these systems.

\section{Conclusion}

The article has presented a study of the decrease in global warming potential of wheat production and combined heat and power production based on a integrated solution. The wheat straw is used in thermal gasification to produce fuel for the CHP plant, while the GBC contains carbon and nutrients which is recycled to the next year's wheat production. Based on the results of the study, the main conclusions are that:

1. utilization of straw from wheat fields for heat and power production has a positive impact on the GWP of the total system, mainly due to the substituted electricity production.

2. Decreasing the carbon conversion of the gasifier, and thus allowing more carbon in the GBC, at the expense of the gasifier efficiency, further improved the GWP of the system. This result will hold despite 18\% and 19\% decrease in the carbon soil sequestration effect for case 1 and 2, respectively.

3. At a carbon conversion of $80 \%$ and $86 \%$, the system was climate change mitigating in terms of $\mathrm{kWh}$ produced for case 1 and 2, respectively. However, before deciding on the appropriate CC in a specific area, the products substituted must be analysed with great care.

These conslusions underline the importance of considering the GBC from the LT-CFB gasifier as an important fertilizer and soil amendment product. However, taking into account the possible changes in the soil's water retention, the positive effect on the environmental impact can be demonstrated as even greater.

\section{Acknowledgements}

This study was financially supported by the Villum Foundation.

\section{References}

[1] IPCC, Fourth Assessment Report: Climate Change 2007: The AR4 Synthesis Report, Geneva: IPCC, 2007.

[2] IPCC, Fourth Assessment Report: Climate Change 2007: Working Group III Report: Mitigation of Climate Change, Geneva: IPCC, 2007.

[3] J. Ahrenfeldt, T. P. Thomsen, U. Henriksen, L. R. Clausen, Biomass gasification cogeneration - a review of state of the art technology and near future perspectives, Applied Thermal Engineering 50 (2) (2013) 1407 - 1417, <ce:title>Combined Special Issues: \{ECP\} 2011 and \{IMPRES\} 2010</ce:title>. doi:http://dx.doi.org/10.1016/j.applthermaleng.2011.12.040.

[4] S. N. Djomo, N. Witters, M. V. Dael, B. Gabrielle, R. Ceulemans, Impact of feedstock, land use change, and soil organic carbon on energy and greenhouse gas performance of biomass cogeneration technologies, Applied Energy 154 (2015) 122 - 130. doi:http://dx.doi.org/10.1016/j.apenergy.2015.04.097.

URL http://www. sciencedirect.com/science/article/pii/S0306261915005607

[5] C. Sastre, Y. González-Arechavala, A. Santos, Global warming and energy yield evaluation of spanish wheat straw electricity generation - a $\{$ LCA $\}$ that takes into account parameter uncertainty and variability, Applied Energy 154 (2015) $900-911$. doi:http://dx.doi.org/10.1016/j.apenergy.2015.05.108.

URL http://www.sciencedirect.com/science/article/pii/S0306261915007412

[6] J. Yang, B. Chen, Global warming impact assessment of a crop residue gasification project-a dynamic $\{\mathrm{LCA}\}$ perspective, Applied Energy 122 (2014) 269 - 279. doi:http://dx.doi.org/10.1016/j.apenergy.2014.02.034.

URL http://www.sciencedirect.com/science/article/pii/S0306261914001706

[7] R. Parajuli, S. Løkke, P. A. østergaard, M. T. Knudsen, J. Schmidt, T. Dalgaard, Life cycle assessment of district heat production in a straw fired $\{$ CHP $\}$ plant, Biomass and Bioenergy 68 (2014) 115 - 134. doi:http://dx.doi.org/10.1016/j.biombioe.2014.06.005. URL http://www.sciencedirect.com/science/article/pii/S0961953414003079

[8] B. M. Petersen, M. T. Knudsen, J. E. Hermansen, N. Halberg, An approach to include soil carbon changes in life cycle assessments, Journal of Cleaner Production 52 (0) (2013) 217 - 224. doi:http://dx.doi.org/10.1016/j.jclepro.2013.03.007.

[9] G. Guest, F. Cherubini, A. H. Strã smman, The role of forest residues in the accounting for the global warming potential of bioenergy, GCB Bioenergy 5 (4) (2013) 459-466. doi:10.1111/gcbb.12014. URL ht tp://dx.doi.org/10.1111/gcbb.12014

[10] F. Cherubini, A. H. Stromman, E. Hertwich, Effects of boreal forest management practices on the climate impact of $\mathrm{CO} 2$ emissions from bioenergy, Ecological Modelling 223 (1) (2011) 59-66. doi:10.1016/j.ecolmodel.2011.06.021. 
[11] K. Kuligowski, T. G. Poulsen, G. H. Rubak, P. Sorensen, Plant-availability to barley of phosphorus in ash from thermally treated animal manure in comparison to other manure based materials and commercial fertilizer, European Journal of Agronomy 33 (4) (2010) 293 - 303. doi:http://dx.doi.org/10.1016/j.eja.2010.08.003.

[12] D. Muller-Stover, J. Ahrenfeldt, J. Holm, S. Shalatet, U. Henriksen, H. Hauggaard-Nielsen, Soil application of ash produced by lowtemperature fluidized bed gasification: effects on soil nutrient dynamics and crop response, Nutrient Cycling in Agroecosystems 94 (2-3) (2012) 193-207. doi:10.1007/s10705-012-9533-x.

[13] M. Brandao, A. Levasseur, M. Kirschbaum, B. Weidema, A. Cowie, S. V. Jorgensen, M. Z. Hauschild, D. Pennington, K. Chomkhamsri, Key issues and options in accounting for carbon sequestration and temporary storage in life cycle assessment and carbon footprinting, The International Journal of Life Cycle Assessment 18 (1) (2013) 230-240. doi:10.1007/s11367-012-0451-6.

[14] V. Hansen, D. Müller-Stöver, J. Ahrenfeldt, J. K. Holm, U. B. Henriksen, H. Hauggaard-Nielsen, Gasification biochar as a valuable by-product for carbon sequestration and soil amendment, Biomass and Bioenergy 72 (2015) 300 - 308. doi:http://dx.doi.org/10.1016/j.biombioe.2014.10.013. URL http: //www. sciencedirect.com/science/article/pii/S0961953414004693

[15] T. L. T. Nguyen, J. E. Hermansen, L. Mogensen, Environmental performance of crop residues as an energy source for electricity production: The case of wheat straw in denmark, Applied Energy 104 (0) (2013) 633 - 641. doi:http://dx.doi.org/10.1016/j.apenergy.2012.11.057.

[16] T. L. T. Nguyen, J. E. Hermansen, R. G. Nielsen, Environmental assessment of gasification technology for biomass conversion to energy in comparison with other alternatives: the case of wheat straw, Journal of Cleaner Production 53 (0) (2013) 138 - 148. doi:http://dx.doi.org/10.1016/j.jclepro.2013.04.004.

[17] B. M. Petersen, J. E. Olesen, T. Heidmann, A flexible tool for simulation of soil carbon turnover, Ecological Modelling 151 (1) (2002) 1 14. doi:http://dx.doi.org/10.1016/S0304-3800(02)00034-0.

[18] B. M. Petersen, J. Berntsen, S. Hansen, L. S. Jensen, Cn-sim- a model for the turnover of soil organic matter. i. long-term carbon and radiocarbon development, Soil Biology and Biochemistry 37 (2) (2005) 359 - 374. doi:http://dx.doi.org/10.1016/j.soilbio.2004.08.006.

[19] B. Elmegaard, N. Houbak, et al., Dna-a general energy system simulation tool, in: Proceedings of SIMS, Citeseer, 2005, pp. 1-10.

[20] C. Mutel, Brightway2, a framework for advanced life cycle assessment calculations (2014). URL http://brightwaylca.org/.

[21] S. V. Vassilev, D. Baxter, L. K. Andersen, C. G. Vassileva, An overview of the chemical composition of biomass, Fuel 89 (2010) $913-933$.

[22] ecoinvent Centre 2013, ecoinvent centre (2013), ecoinvent data v3.1., swiss Centre for Life Cycle Inventories, Dübendorf, 2013, retrieved from: www.ecoinvent.org.

[23] NaturErhvervstyrelsen, Vejledning om gØdsknings- og harmoniregler, Tech. rep., Ministeriet for Fødevarer, Landbrug og Fiskeri (2013).

[24] G. Myhre, D. Shindell, F. M. Bréon, W. Collins, J. Fuglestvedt, J. Huang, D. Koch, J. Lamarque, D. Lee, B. Mendoza, T. Nakajima, A. Robock, G. Stephens, T. Takemura, H. Zhang, 2013: Anthropogenic and natural radiative forcing. in: Climate change 2013: The physical science basis. contribution of working group i to the fifth assessment report of the intergovernmental panel on climate change, Tech. rep., Intergovernmental Panel on Climate Change, [Stocker, T.F., D. Qin, G.-K. Plattner, M. Tignor, S.K. Allen, J. Boschung, A. Nauels, Y. Xia, V. Bex and P.M. Midgley (eds.)]. Cambridge University Press, Cambridge, United Kingdom and New York, NY, USA, pp. 659 - 0740 (2013). doi:doi:10.1017/ CBO9781107415324.018.

[25] DMI, Danmarks climate 2014, Danmarks Meteorologiske Institut, 2014. URL http: //www.dmi.dk/en/vejr/arkiver/decadal-mean-weather/

[26] T. Nemecek, J. Schnetzer, Methods of assessment of direct field emissions for lcis of agricultural production systems, Agroscope ReckenholzTlniNRn Research Station ART.

[27] E. research Centre of the Netherlands, Phyllis2, database for biomass and waste,. URL https : //www .ecn.nl/phyllis2

[28] M. Hauschild, J. Potting, Spatial differentiation in life cycle impact assessment - the edip2003 methodology, Tech. rep., Institute for Product Development - Technical University of Denmark (2005).

[29] R. Roy, R. Misra, J. Lesschen, E. Smaling, Assessment of soil nutrient balance: Approaches and methodologies, Tech. rep., FOOD AND AGRICULTURE ORGANIZATION OF THE UNITED NATIONS (2003). URL ftp: //ftp. fao.org/docrep/fao/006/y5066e/y5066e00.pdf

[30] P. d. Willigen, An analysis of the calculation of leaching and denitrification losses as practised in the nutmon approach., Rapport-Plant Research International (18).

[31] P. Nielsen, A. Nielsen, B. Weidema, R. Dalgaard, N. Halberg, Lca food data base (2003). URL www. lcaf ood. dk.

[32] S. Eggleston, L. Buendia, K. Miwa, 2006 IPCC guidelines for national greenhouse gas inventories [recurso electrónico]: industrial processes and product use., Kanagawa, JP: Institute for Global Environmental Strategies, 2006.

[33] W. A. Asman, Ammonia emission in Europe: updated emission and emission variations, National Institute of Public Health and Environmental Protection Bilthoven, the Netherlands, 1992.

[34] M. Faist Emmenegger, J. Reinhard, R. Zah, SQCB - Sustainability Quick Check for Biofuels, Empa, 2009, intermediate Background Report.

[35] F. Cherubini, G. Guest, A. H. StrÂ, mman, Application of probability distributions to the modeling of biogenic co2 fluxes in life cycle assessment, GCB Bioenergy 4 (6) (2012) 784-798. doi:10.1111/j.1757-1707.2011.01156.x. URL http://dx.doi.org/10.1111/j.1757-1707.2011.01156.x

[36] F. Joos, M. Bruno, R. Fink, U. Siegenthaler, T. F. Stocker, C. Le Quere, J. L. Sarmiento, An efficient and accurate representation of complex oceanic and biospheric models of anthropogenic carbon uptake, Tellus B 48 (3) (1996) 397-417. doi:10.1034/j.1600-0889.1996.t01-200006.x.

URL http://dx.doi.org/10.1034/j.1600-0889.1996.t01-2-00006.x

[37] F. Joos, I. C. Prentice, S. Sitch, R. Meyer, G. Hooss, G.-K. Plattner, S. Gerber, K. Hasselmann, Global warming feedbacks on terrestrial carbon uptake under the intergovernmental panel on climate change (ipcc) emission scenarios, Global Biogeochemical Cycles 15 (4) (2001) 891-907. doi:10.1029/2000GB001375. 
URL http://dx.doi.org/10.1029/2000GB001375

[38] T. Nemecek, T. Kagi, Life cycle inventories of agricultural production systems, Tech. rep., Reckenholz-Tanikon Research Station ART, ecoinvent report No. 15 (2007).

[39] M. Green, et al., Energy in pesticide manufacture, distribution and use., Energy in world agriculture (2) (1987) 166-177.

[40] M. G. Bhat, B. C. English, A. F. Turhollow, H. O. Nyangito, Energy in synthetic fertilizers and pesticides: revisited, ORNL/Sub/90-99732/2. Oak Ridge National Laboratory, Oak Ridge, TN, US Dept. Energy.

[41] D. Hartley, H. Kidd, et al., The agrochemicals handbook. 2nd edition, The Royal Society of Chemistry, 1987.

[42] C. Tomlin (Ed.), The Pesticide Manual, 11th edition, British Crop Protection Council, 1997.

[43] B. M. Petersen, J. Berntsen, Ther turnover of soil organic matter on different farm types, DARCOFenews, http://orgprints .org/4665/1/4665.PDF (September 2003). 